\title{
Mice Lacking Glypican 4 Display Juvenile Hyperactivity and Adult Social Interaction Deficits
}

\author{
Cari Dowling and Nicola J. Allen* \\ Molecular Neurobiology Laboratory, Salk Institute for Biological Studies, La Jolla, CA, USA
}

Accepted: 14 December 2018

Published: 20 December 2018

\begin{abstract}
Glypican 4 (Gpc4) is a heparan sulfate proteoglycan that regulates glutamatergic synapse formation and function in the developing brain. Gpc4 KO mice have been shown to have decreased excitatory synapse number and less synaptic GluA1 AMPA receptors, leading to decreased synaptic transmission. Further, decreased expression of Gpc 4 has been linked to autism spectrum disorder (ASD). Gpc4 is expressed by both astrocytes and neurons during postnatal development, with astrocyte expression higher in juvenile stages, and neuronal expression increasing with maturation. We therefore asked if mice lacking Gpc4 display behavioral alterations that are consistent with loss of GluA1 or ASD, and if so if they occur at juvenile ages when astrocyte Gpc4 is high, or at adult ages when both astrocytes and neurons express Gpc4. We found that juvenile (P14) Gpc4 KO mice display hyperactivity in the open field, which is corrected in adult mice (3 month). Adult Gpc4 KO mice show deficient behavior in social novelty, whilst non-social behaviors such as working memory and anxiety are unaffected. Thus, Gpc4 KO mice show age-specific behavioral alterations that are consistent with altered synaptic levels of GluA1 and behaviors associated with ASD.
\end{abstract}

Keywords: Astrocyte, synapse, AMPA, neurodevelopment

\section{INTRODUCTION}

Alterations in neuronal synaptic development and plasticity can have profound impact on circuit function and behavioral performance. In development the formation of synapses is regulated by interactions between pre and post-synaptic neurons, for example adhesion molecules at the synaptic site, as well as by extrinsic cues from neighboring astrocytes [1,2]. Astrocytes increase both the number of synapses that neurons form, and the function of those synapses, via the secretion of multiple signals [3]. We identified that astrocytes induce formation of immature glutamater-

\footnotetext{
${ }^{*}$ Correspondence to: Nicola J. Allen, Molecular Neurobiology Laboratory, Salk Institute for Biological Studies, 10010 North Torrey Pines Rd, La Jolla, CA, 92037, USA. Tel.: +1 8584534100 /Ext 2129; E-mail: nallen@salk.edu.
}

gic synapses via the release of glypican $4(\mathrm{Gpc} 4)$, and do so by increasing synaptic levels of the GluA1 subunit of the AMPA glutamate receptor (AMPAR) [4]. As the development of the appropriate synaptic connections, and the ability to alter synaptic levels of AMPARs, are both important factors underlying behavioral performance, we set out to determine if mice lacking Gpc4 show any deficits in a series of behavioral tasks.

Glypicans are a family of heparan sulfate proteoglycans (HSPGs), of which there are six members in mammals [5]. Each glypican consists of a compact core protein of $\sim 60 \mathrm{kDa}$, along with multiple heparan sulfate chains attached near the C-terminus. Glypicans are attached to the extracellular membrane of the cell via a GPI-anchor (for which they earn their name), and exist in this cell-attached form, or undergo 
cleavage near the $\mathrm{C}$-terminus to release a soluble form to the extracellular space. Glypicans have important roles in the development of many tissues, including the brain [6, 7]. A well-established role of glypicans is as modulators of growth factor signaling, for example binding fibroblast growth factor (FGF) [8]. The outcome of this binding depends on the location of the glypican - if it is in the cleaved form in the extracellular space it will sequester the growth factor and stop it signaling, whereas if it is in the membrane attached form it can enhance signaling by localizing the ligand close to its receptor.

Recently glypicans, in particular Gpc4, have been demonstrated to play important roles in neuronal synapse formation and function $[4,9,10]$. Glypicans are expressed by both astrocytes and neurons during postnatal development $[4,11,12]$. In the mouse brain, including in the hippocampus, astrocyte expression of Gpc4 mRNA is high in the first two postnatal weeks and decreases after this, a time period when synapses are forming and being remodeled $[4,11]$. Subsets of neurons e.g. dentate granule neurons in the hippocampus, upregulate $\mathrm{Gpc} 4$ in the second to third postnatal week $[4,11]$. We identified that astrocytes secrete Gpc4, and this soluble Gpc4 induces nascent synapse formation by increasing levels of GluA1 AMPARs on the postsynaptic dendrite [4]. We further identified that $\mathrm{Gpc} 4$ does this by signaling through presynaptic protein tyrosine phosphatase receptor delta (PTPRd) to upregulate secretion of the AMPAR clustering factor neuronal pentraxin 1 (NP1), which then clusters GluA1 AMPA receptors on the postsynaptic dendrite [13]. Neuronal Gpc4 is membrane attached and present in presynaptic terminals, where it interacts with postsynaptic Lrrtm4 to induce synapse formation $[9,10]$, as well as with presynaptic PTPRs [14]. Thus, the cell-type expression, and synaptogenic mode of interaction of Gpc4, change across development.

Gpc4 KO mice are viable and born at expected Mendelian ratios [4, 13]. Analysis of synapse formation and function in Gpc4 KO mice revealed a deficit in synaptic strength in CA1 hippocampal neurons at postnatal day (P) 12, manifest as a $30 \%$ decrease in the average amplitude of individual excitatory synaptic events (mEPSCs), with a smaller but still significant decrease present at P24 [4]. This decrease in mEPSC amplitude is correlated with a reduction in GluA1 AMPARs at the postsynaptic density. The effects on synapse formation and synaptic GluA1 are not restricted to the hippocampus. For example, in the developing visual system there is a $25 \%$ decrease in synapse number and synaptic GluA1 in the superior colliculus at P6 [13]. Further, astrocyte-specific Gpc4 KO mice have the same phenotype as global Gpc4 $\mathrm{KO}$ mice in relation to impaired neuronal secretion of NP1 at P6, highlighting the important role of astrocyte Gpc4 in early stages of synaptic development [13].

Alterations in glypican family members have been linked to a number of different neurological disorders, including autism spectrum disorder (ASD; Gpc4,6), schizophrenia (Gpc4,5,6), neuroticism (Gpc6) and attention-deficit hyperactivity disorder (ADHD; Gpc6) [15-18]. For example, decreased expression of Gpc4 has been identified in rare sporadic cases of ASD, caused by point mutations in regions that regulate Gpc4 expression [19]. Given the role for Gpc4 in synaptic development and function, and the link to ASD, we set out to ask if absence of Gpc4 has any effect on behavioral performance in mice, focusing on those tasks that are known to be altered in GluA1 KO mice, and are further commonly used to assess mutations linked to ASD.

\section{MATERIALS AND METHODS}

Mice

All mouse procedures were approved by the Salk Institute IACUC (Institutional Animal Care and Use Committee). Mice were group housed with their littermates at weaning at P21, and kept on a 12 hour light: 12 hour dark cycle, with ad libitum access to food and water. Mice remained group housed throughout the testing period.

The mouse strain used for this research project, B6;129S5-Gpc4tm1Lex/Mmucd, identification number 032331-UCD, was obtained from the Mutant Mouse Regional Resource Center, a NCRR-NIH funded strain repository, and was donated to the MMRRC by Genentech, Inc., and are as previously described and validated for loss of Gpc4 mRNA and protein $[4,13]$. The presence of the mutant Gpc4 allele was determined by PCR genotyping. Mice were maintained on a C57B16/J background (wild type mice obtained from Jackson Labs, C57B16/J; 000664), or back-crossed for 6 generations to FVB (wild type mice obtained from Jackson Labs, FVB/NJ; 001800). The back-crossing to FVB was initiated as our previous experience working with the Gpc4 KO line suggested there may be perinatal lethality when the mice were maintained on a pure C57B16/J background [4], an effect we no 
longer observed when the KO mice were rederived, suggesting a facility-specific effect. We performed behavioral testing on mice from both genetic backgrounds, as the background can impact behavioral performance [20].

Gpc4 is on the $\mathrm{X}$ chromosome, so to obtain mice for experiments breeding was performed as $\mathrm{Gpc} 4+$ /female to $\mathrm{Gpc} 4+/ \mathrm{y}$ male, and male mice that were Gpc4 +/y (WT) or Gpc4-/y (KO) were compared. It is not possible to obtain littermate WT and Gpc4 KO female mice, and female heterozygous mice are mosaic for Gpc4 so not a valid control, so female mice were not analyzed in this study.

\section{Overview of behavioral testing schedule}

Cohorts of littermate WT and KO mice were tested together, and came from multiple different breeding pairs. For P14 and P21 analysis on a C57B16/J background, mice came from 5 different litters from 3 breeding pairs. The same mice were tested at both P14 and P21, and these were separate cohorts from those tested at 3 months. For 3 month analysis on a C57Bl6/J background, mice came from 10 litters from 9 different breeding pairs. For 3 month analysis on an FVB background mice came from 10 different litters from 5 different breeding pairs. For analysis at 3 months all mice were run on each test, as outlined below. The investigator was blinded to the genotype of the mice during testing and analysis. All tests were conducted in the morning of the testing day in the following order, a similar test order to that described in [20]. Day 1: Neurological screen and open field test (1 hour after neurological screen); Day 3: Y-maze; Day 4: Light-Dark test; Day 11: Social interaction, one week after previous tests.

\section{Neurological screen}

Gross sensory and neuromuscular function was assessed using a subset of tests adapted from the primary SHIRPA protocol [21] and similar to those described in $[20,21]$. These are subjective tests with performance determined by the observer, and are designed to identify gross differences in performance that would indicate further detailed testing is required in a particular area. Performance was measured on a scale of -3 to 3 , with $-3=$ inability to perform, $0=$ normal response, and $3=$ extreme heightened response.

Corneal Reflex: a small plastic bulb was used to administer a puff of air directly on the eye. The score was recorded by how fast the mouse reacted to the air puff. Ear Twitch: the tip of a pen was used to tickle the hair inside the ear. The score was recorded by how quickly and vigorously the mouse responded to the stimulus. Surface grab: the mouse was held by the tail and lowered toward an object, and scored based on distance from the object the mouse began to reach for it. Pupil constriction: in a dark room, a flashlight was shone directly into the eye of the mouse, and the score recorded based on how quickly the pupil dilated/constricted due to the light source. Olfactory response: chocolate was used to stimulate an olfactory response, and response recorded based on the reaction time and intensity of reaction. Startle response: a clicker was used to induce a startle, and scored based on freezing behavior, or if the mouse jumped. Grip strength: the mouse was placed on a wire rack that was turned upside down for 30 seconds, and the hang time recorded. A $T$-test was used to determine if there were significant differences between genotypes for each test.

\section{Open field}

The open field test was used to measure overall locomotor activity to test for gross deficits in motor performance (decreased movement), or hyperactivity (increased movement). Further, the test was used to determine anxiety by measuring the time the mouse spent in the center of the arena (less anxious) compared to the edge (anxious). Mice were individually placed into clear boxes $(40.6 \times 40.6 \times 38.1 \mathrm{~cm})$ surrounded by optical sensors that measure horizontal (ambulatory) and vertical (rearing) activity, with movement detected by beam breaks. Juvenile mice were assessed for 5 minutes (P14) or 20 minutes (P21); adult mice were assessed for 60 minutes. When comparing the total performance in each condition e.g. ambulatory counts in 60 minutes, a $T$-test was used to compare genotypes. A two-way repeated measures ANOVA was used to determine if there was a significant difference in performance across the test period ( 5 minute bins) between genotypes (genotype $\times$ time point). When comparing time spent in the center vs time at the edge a two-way ANOVA (HolmSidak) was used to determine if there were significant differences within (center vs edge) and across (WT vs $\mathrm{KO}$ ) genotypes.

\section{Y-maze spontaneous alternation test}

The Y-Maze spontaneous alternation test was used to examine working spatial memory [22]. The maze consists of 3 equally-spaced arms $(15$ " $\mathrm{L} \times 3$ " $\mathrm{W} \times 5$ " 
$\mathrm{H}$ per arm) made of black plastic (designated arms A, $\mathrm{B}, \mathrm{C})$. The mouse explores the maze for 5 minutes (minimum of 12 arm entries) and arm entries are grouped into consecutive sequences of 3 (i.e., ACB$\mathrm{CAC}=\mathrm{ACB}, \mathrm{CBC}, \mathrm{BCA}, \mathrm{CAC})$. An entry sequence is an alternation when it includes $\mathrm{A}, \mathrm{B}$, and $\mathrm{C}$ in any order (i.e. BCA) but not when the same arm is entered more than once (i.e. CBC). Spontaneous alternation is calculated as: (Alternations) / (Number of arm entries - 2) $* 100=\%$ Spontaneous alternation. A $T$-test was used to determine if there were significant differences between genotypes, and if within a genotype the mice performed significantly better than chance (50\% alternation).

\section{Light-dark chamber}

The light-dark test was used to measure anxiety [23]. A dark box was placed over one third of the open field arena, and the time the mouse spent in the dark and the light areas over 15 minutes was recorded. A two-way ANOVA (Holm-Sidak) was used to determine if there were significant differences in time spent in each zone within (dark vs light) and across (WT vs KO) genotypes. The number of entries into the light zone from the dark zone were recorded, and compared across genotypes using a $T$-test.

\section{Three chamber social interaction}

To measure sociability we used the three chamber social interaction test [24], consisting of a 3 chamber arena measuring $20 \mathrm{~cm} \times 40 \mathrm{~cm}$ per chamber, initially separated by dividers. For Social Interaction a subject mouse was placed in the center chamber and allowed to habituate for 5 minutes, then a stimulus mouse unfamiliar to the subject mouse (matched by strain, age and gender) was put in a wire cup and placed into 1 of the two side chambers, while an empty wire cup was placed in the other side chamber. The dividers were removed and the subject mouse allowed to explore all 3 chambers for 10 minutes, and video-recorded for off-line analysis. In the second phase of the test, Social Novelty, the test was repeated but the empty cup replaced with a cup containing a second novel mouse. The duration of time the subject mouse spent in each chamber (stimulus mouse, middle, empty cup/novel mouse), and in contact with the stimulus mouse or empty cup/novel mouse was recorded. A two-way ANOVA (Holm-Sidak) was used to determine if there were significant differences in time spent in each chamber, or in contact with the stimulus mouse, within (empty or stimulus vs novel or stimulus) and across (WT vs KO) genotypes.

\section{Statistics and data presentation}

Graphs were made in Prism, and individual data points represent each mouse. Statistics were performed in Sigmaplot and Prism, and each test is outlined in the appropriate methods section and figure legend.

\section{RESULTS}

As Gpc4 is on the $\mathrm{X}$ chromosome, all behavioral testing was performed on male WT and KO mice, in order to allow comparison of littermates (see Methods for detailed breeding information).

\section{Juvenile Gpc4 KO mice show hyperactive behavior in an open field}

We first asked if juvenile (P14) Gpc4 KO mice on a C57B16/J background show altered baseline behavior, as this is the age at which we observed weaker synapses in the hippocampus [4]. Mice were assessed using the open field test, by placing them in an arena and tracking their movement for $5 \mathrm{~min}$ utes (termed ambulatory count) (Fig. 1A). Both total movement (ambulatory counts in 5 minutes: P14 WT $19.1 \pm 6.5, \mathrm{KO} 85.0 \pm 24.0 ; T$-test $p=0.007 ; \mathrm{N}=10$ WT, 7 Gpc4 KO; Fig. 1B) and average velocity (average velocity over 5 minutes: P14 WT $1.08 \pm 0.33, \mathrm{KO}$ $3.01 \pm 0.50 ; p=0.004$; Fig. 1C) were significantly increased in the Gpc4 KO, suggestive of hyperactive behavior. We then asked if the hyperactivity was still present in the same mice at P21, a time when we previously observed a lesser deficit in synaptic strength in the hippocampus [4]. To provide a direct comparison to the $\mathrm{P} 14$ condition we analyzed the first 5 minutes of movement in the open field, and found no significant difference between the WT and Gpc4 KO (ambulatory counts in 5 minutes: P21 WT $460 \pm 62, \mathrm{KO} 310 \pm 50 ; T$-test $p=0.10 ; \mathrm{N}=10$ WT, 7 Gpc4 KO; Fig. 1D) and (average velocity over 5 minutes: P21 WT $11.0 \pm 1.3$, KO $8.5 \pm 0.9$; $p=0.18$; Fig. 1E). We then analyzed the whole 20 minute recording period, and again found no difference between the WT and Gpc4 KO in total movement (ambulatory counts in 20 minutes: P21 WT $1568 \pm 157$, KO $1385 \pm 142 ; p=0.42$; Fig. 1F) or average velocity (average velocity over $20 \mathrm{~min}$ utes: P21 WT 11.8 \pm 1.0 , KO 9.9 $\pm 0.5 ; p=0.17$; 

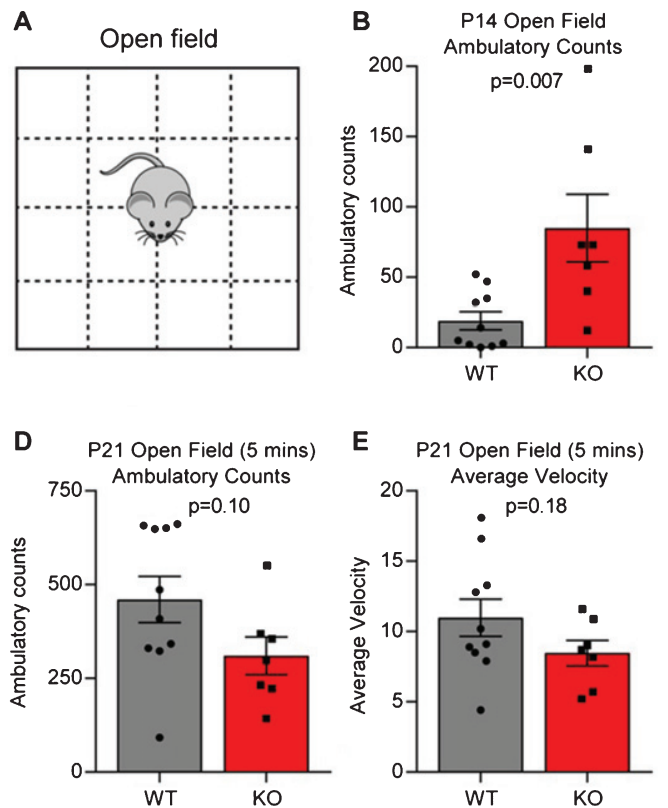
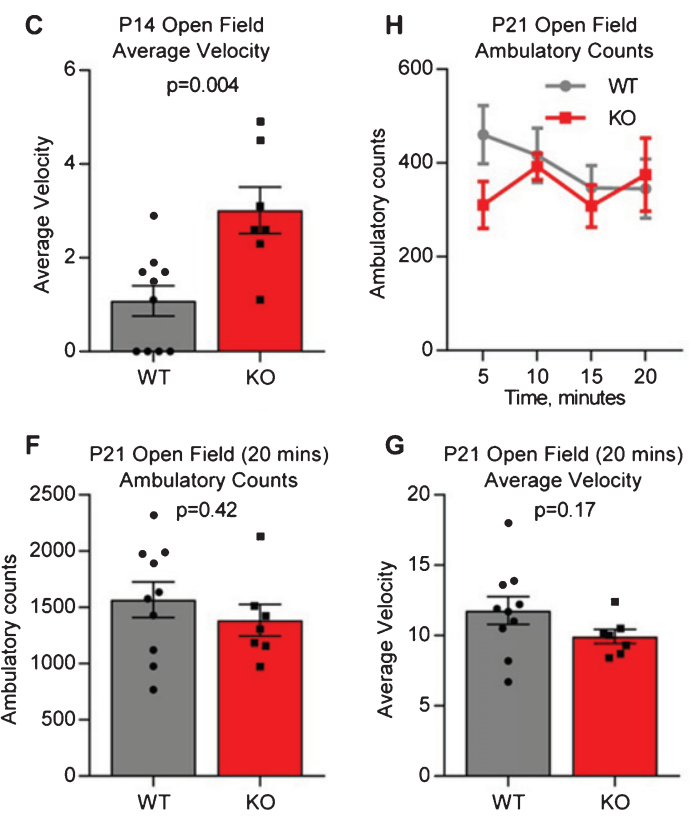

Fig. 1. Juvenile Gpc4 KO mice are hyperactive in an open field. A. Schematic of the open-field chamber, dashed lines represent beams that detect movement. B-C. P14 Gpc4 KO mice are more active than WT over a 5 minute period, in total distance moved (B) and velocity (C). N = $10 \mathrm{WT}, 7 \mathrm{Gpc} 4 \mathrm{KO}$, statistics by T-test, bar graph mean \pm s.e.m., individual points represent mice. D-H. P21 Gpc4 KO mice show activity indistinguishable from WT over a 5 (D-E) and 20 (F-G) minute period, in total distance moved (D,F) and velocity (E,G). N=10 WT, $7 \mathrm{Gpc} 4 \mathrm{KO}$, statistics by $T$-test, bar graph mean \pm s.e.m., individual points represent mice. H. P21 ambulatory counts plotted in 5 minute bins, show no difference in movement over time between WT and Gpc4 KO.

Fig. 1G). Plotting the ambulatory counts in 5 minute bins showed a trend towards the expected decrease in ambulation with time for the WT, whereas Gpc4 KO mice showed equal movement at each timepoint, however there was no significant difference between the groups (2-way RM ANOVA: genotype $p=0.42$; time point $p=0.45$; Fig. $1 \mathrm{H}$ ). Thus there is a transient hyperactivity in Gpc4 KO mice at P14, matching the time period when astrocytes and neurons express Gpc4.

\section{Adult Gpc4 KO mice have no overt neurological deficits}

To determine if developmental deficits in synapse formation and function have long term consequences on behavior, the rest of our studies were conducted on adult Gpc4 KO and WT mice, at 3 months of age. In addition to conducting testing on mice on a C57B16/J genetic background, we also crossed the mice onto an FVB background (see Methods). This was to determine if the genetic background of the mice would interact with the Gpc4 $\mathrm{KO}$ and cause alterations in behavioral testing [20]. We first performed a battery of neurological tests to determine if there were gross deficits in hearing, vision, smell or grip strength in the mice. We found no difference in any of these parameters between Gpc4 KO and WT mice on either the C57B16/J (Table 1A) or FVB (Table 1B) genetic backgrounds. Gpc4 KO mice were however $\sim 10 \%$ lighter than the WT, significantly so on an FVB background (C57B16/J: WT 27.9 $\pm 0.6 \mathrm{~g}, \mathrm{Gpc} 4 \mathrm{KO} 26.5 \pm 0.7 \mathrm{~g}$; $T$-test $p=0.15 ; \mathrm{N}=15 \mathrm{WT}, 13 \mathrm{Gpc} 4 \mathrm{KO})(\mathrm{FVB}: \mathrm{WT}$ $33.5 \pm 1.0 \mathrm{~g}, \mathrm{Gpc} 4 \mathrm{KO} 30.6 \pm 0.7 \mathrm{~g} ; p=0.03 ; \mathrm{N}=16$ WT, 16 Gpc4 KO).

\section{Adult Gpc4 KO mice show normal behavior in an open field}

We performed open field testing to determine if adult Gpc4 KO mice show any alteration in mobility or anxiety-related behavior. Mice were placed in the open field chamber and ambulatory counts (distance moved), average velocity and vertical counts (rearing) recorded for 60 minutes (Fig. 2A). On a C57B16/J background, there was no significant difference in total distance covered (ambulatory counts in 60 minutes: WT $9797 \pm 716, \mathrm{KO} 9946 \pm 722 ; T$ test $p=0.88 ; \mathrm{N}=15 \mathrm{WT}, 14 \mathrm{Gpc} 4 \mathrm{KO}$; Fig. 2B), average velocity of movement (average velocity over 
Table 1

Neurological screen of Gpc4 KO and WT mice at 3 months

\begin{tabular}{lccc}
\hline A & \multicolumn{3}{c}{ C57BI6 } \\
\cline { 2 - 4 } & WT (15) & Gpc4 KO (13) & $p$-value (T-test) \\
\hline Eye Blink & $0.00 \pm 0.00$ & $0.00 \pm 0.00$ & $n / a$ \\
Ear Twitch & $-0.13 \pm 0.24$ & $0.23 \pm 0.17$ & 0.22 \\
Olfactory & $-1.07 \pm 0.37$ & $-0.62 \pm 0.31$ & 0.36 \\
Surface Grab & $-0.53 \pm 0.26$ & $-0.92 \pm 0.33$ & 0.36 \\
Pupil Reflex & $-0.13 \pm 0.09$ & $-0.54 \pm 0.27$ & 0.17 \\
Startle Response & $0.00 \pm 0.10$ & $0.00 \pm 0.00$ & 1.00 \\
Wire Hang & $28.7 \pm 1.0$ & $29.2 \pm 0.8$ & 0.66 \\
Weight & $27.9 \pm 0.6$ & $26.5 \pm 0.7$ & 0.15 \\
\hline B & \multicolumn{3}{c}{ FVB } \\
& WT $(16)$ & Gpc4 KO $(16)$ & $p$-value $(T$-test $)$ \\
\hline Eye Blink & $0.00 \pm 0.00$ & $0.00 \pm 0.00$ & $n / a$ \\
Ear Twitch & $-0.25 \pm 0.23$ & $-0.13 \pm 0.20$ & 0.69 \\
Olfactory & $-0.88 \pm 0.33$ & $-0.81 \pm 0.28$ & 0.89 \\
Surface Grab & $-0.19 \pm 0.14$ & $0.00 \pm 0.00$ & 0.19 \\
Pupil Reflex & $-0.06 \pm 0.06$ & $-0.06 \pm 0.06$ & 1.00 \\
Startle Response & $0.44 \pm 0.16$ & $0.69 \pm 0.22$ & 0.36 \\
Wire Hang & $19.9 \pm 2.7$ & $23.9 \pm 2.1$ & 0.25 \\
Weight & $33.5 \pm 1.0$ & $30.6 \pm 0.7$ & 0.03 \\
\hline A.
\end{tabular}

A. Mice on a C57B16/J genetic background. B. Mice on an FVB background. $\mathrm{N}$ for each condition in brackets. All ratings are on a scale of -3 to +3 (where 0 is normal performance, -3 inability to perform, +3 heightened response), except for wire hang (in seconds) and weight (in grams). Data presented as mean \pm s.e.m. Statistics by $T$-test.

60 minutes: WT $15.5 \pm 1.3, \mathrm{KO} 16.0 \pm 1.2 ; p=0.79$; Fig. 2C) or rearing (vertical counts in 60 minutes: WT $906 \pm 76$, KO $901 \pm 75 ; p=0.96$; Fig. 2D) between the Gpc4 KO and WT. We further plotted the ambulatory counts in 5 minute bins to determine if there was any difference in the trajectory of movement between the WT and Gpc4 KO (Fig. 2E). There was no significant difference in movement between the WT and Gpc4 KO at any timepoint, but there was a significant decrease in total movement over time in both the WT and Gpc4 KO, demonstrating the expected decrease in exploratory behavior that is normally observed in mice in an open field test (2-way RM ANOVA: genotype $p=0.89$; time point $p<0.001)$. We further asked if the mice showed any sign of anxiety by analyzing the time spent in the center (less anxious) of the open field chamber vs around the edge (more anxious) (Fig. 2F). Both WT and Gpc4 KO mice spent significantly more time in the edge zone than the center zone, with no differences detected between genotypes (WT: time center $1395 \pm 91 \mathrm{sec}$, edge $2205 \pm 91 \mathrm{sec} ; p<0.001$; KO: time center $1309 \pm 69 \mathrm{sec}$, edge $2291 \pm 69 \mathrm{sec}$; $p<0.001$; statistics 2-way ANOVA; $\mathrm{N}=11 \mathrm{WT}, 10$ Gpc4 KO; Fig. 2G). There was also no difference in the number of entries to the center zone from the edge zone between genotypes (WT: $749 \pm 80$ entries, KO: $736 \pm 103$ entries; $T$-test $p=0.92$; Fig. $2 \mathrm{H}$ ). Thus both WT and Gpc4 KO mice showed the expected preference for spending more time around the edge of the arena, demonstrating the $\mathrm{Gpc} 4 \mathrm{KO}$ mice do not display any alteration in anxiety.

We performed the same set of analysis on mice on an FVB background. There was no significant difference in total distance covered (ambulatory counts in 60 minutes: WT $13347 \pm 770$, KO $12962 \pm 903$; $T$-test $p=0.75 ; \mathrm{N}=18 \mathrm{WT}, 19 \mathrm{Gpc} 4 \mathrm{KO}$; Fig. 2I) or average velocity of movement (average velocity over 60 minutes: WT $18.5 \pm 0.8$, KO $20.3 \pm 0.6$; $p=0.07$; Fig. 2J), however there was a significant decrease in rearing (vertical counts in 60 minutes: WT $1090 \pm 115$, KO $848 \pm 40 ; p=0.05$; Fig. $2 \mathrm{~K}$ ) between the Gpc4 KO and WT. There was no difference in movement trajectory between the WT and Gpc4 KO when analyzed in 5 minute bins, although the expected decrease in exploratory behavior over time was present in both genotypes (2-way RM ANOVA: genotype $p=0.75$; time point $p<0.001$; Fig. 2L). We further asked if the mice showed any sign of anxiety. Both WT and Gpc4 KO mice spent significantly more time in the edge zone than the center zone, with no differences detected between genotypes (WT: time center $892 \pm 50 \mathrm{sec}$, edge $2707 \pm 50 \mathrm{sec} ; \quad p<0.001 ; \mathrm{KO}$ : time center $839 \pm 52 \mathrm{sec}$, edge $2761 \pm 52 \mathrm{sec} ; p<0.001$; statistics 2-way ANOVA; N=16 WT, $18 \mathrm{Gpc} 4 \mathrm{KO}$; Fig. 2M). Gpc4 KO mice did however show less entries to the center zone (WT: $563 \pm 47$ entries, KO: $436 \pm 24$ entries; $T$-test $p=0.02$; Fig. $2 \mathrm{~N})$. Together this suggests no strong difference in anxiety exists between Gpc4 KO and WT on an FVB background. Thus Gpc4 KO mice on two genetic backgrounds show behavior that is broadly indistinguishable from WT in the open field arena.

\section{Adult Gpc4 KO mice are indistinguishable from WT in working memory performance}

We next asked if Gpc4 KO mice displayed any deficits in a working memory task. We used the Ymaze spontaneous alternation task, where mice are placed in an apparatus consisting of 3 arms in a Y shape, and the order in which they enter and explore each arm over a 5 minute period recorded (Fig. 3A). Mice are naturally inquisitive, so if working memory is intact they are more likely to enter a novel arm than the arm they previously entered, counted as a spontaneous alternation. An alternation rate below 50\% 
A
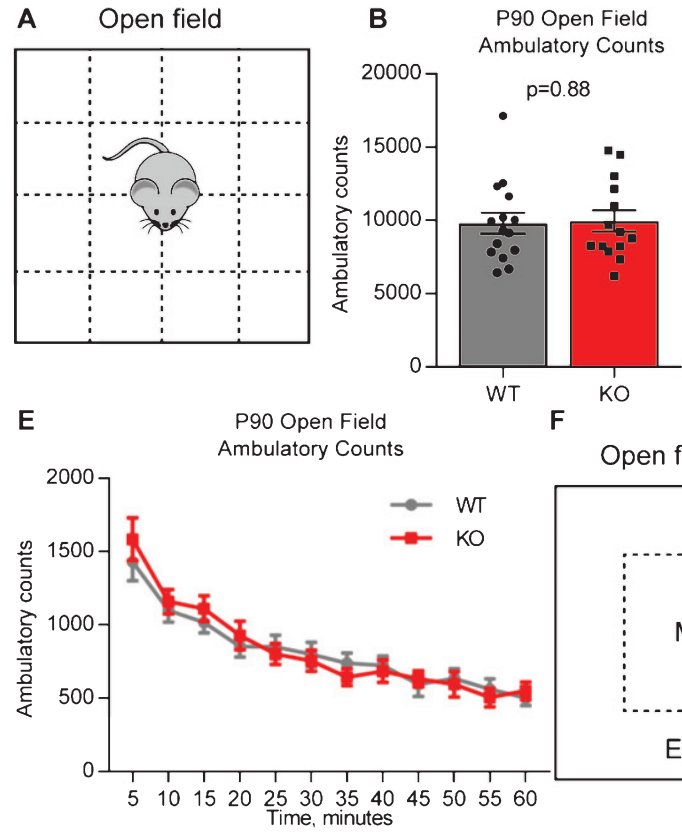

C

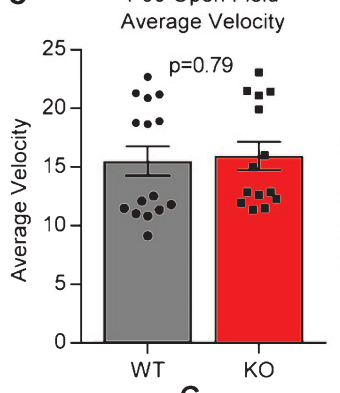

D P90 Open Field

Vertical Counts

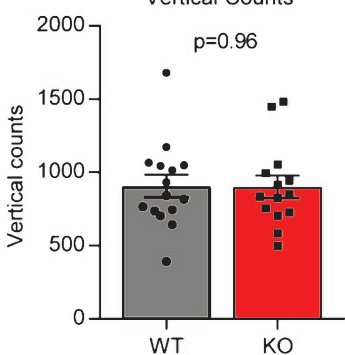

Open Field Zones

Open field, zones

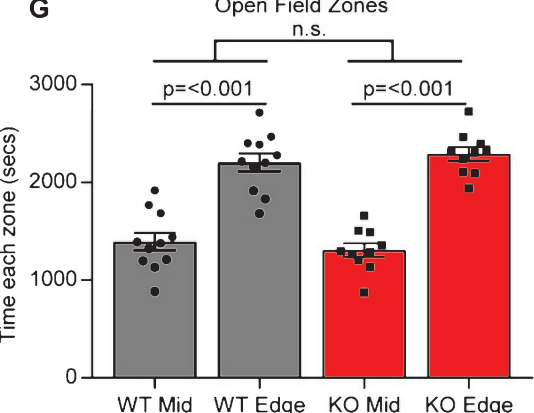

Edge

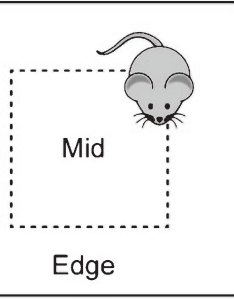

H Open Field Zones

K P9o Open Field $\quad H$

Entries to middle

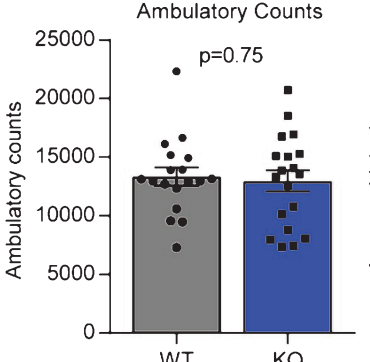

WT
J P90 Open Field Average Velocity

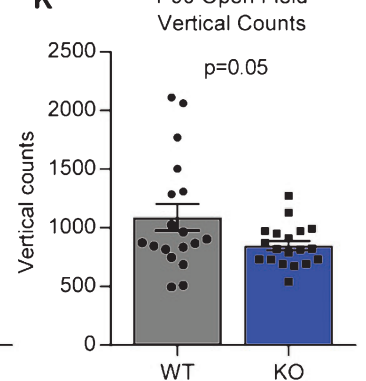

WT Open Field Zones
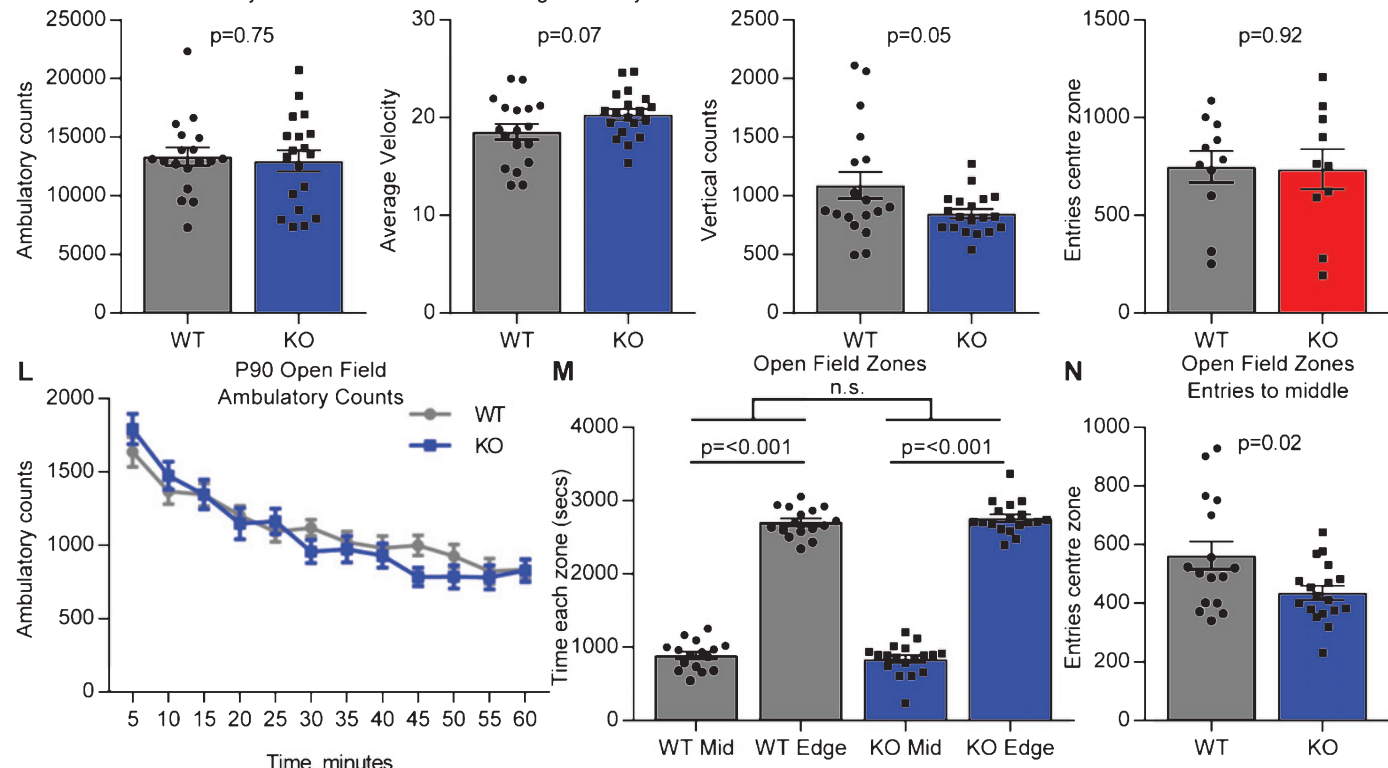

N Open Field Zones Entries to middle

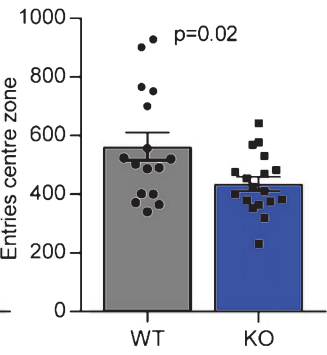

Fig. 2. Adult Gpc4 KO mice perform similar to WT in an open field. A. Schematic of the open-field chamber, dashed lines represent beams that detect movement. B-D. C57B16/J P90 Gpc4 KO mice show the same activity as WT over a 60 minute period, in total distance moved (B), velocity (C) and vertical counts/rearing (D). E. Ambulatory counts in 5 minute bins, no difference in movement over time between WT and Gpc4 KO. N=15 WT, 14 Gpc4 KO, statistics by $T$-test (B-D), bar graph mean \pm s.e.m., individual points represent mice. F. Schematic of the open-field chamber with center and edge zones marked. G-H. Gpc4 KO and WT mice spend similar times to each other in the center and edge zones of the open field $(\mathrm{G})$, and no difference in the number of entries to the center zone $(\mathrm{H})$, showing no anxiety phenotype. $\mathrm{N}=11$ WT, $10 \mathrm{Gpc} 4 \mathrm{KO}$, statistics by 2-way ANOVA (G) or $T$-test $(\mathrm{H})$, bar graph mean \pm s.e.m., individual points represent mice. I-K. FVB P90 Gpc4 KO mice show the same activity as WT over a 60 minute period, in total distance moved (I) and velocity (J), but show significantly less vertical counts/rearing (K). L. Ambulatory counts in 5 minute bins, no difference in movement over time between WT and Gpc4 KO. $\mathrm{N}=18 \mathrm{WT}, 19 \mathrm{Gpc} 4 \mathrm{KO}$, statistics by $T$-test (I-K), bar graph mean \pm s.e.m., individual points represent mice. M-N. Gpc4 KO and WT mice spend similar times in the center and edge zones of the open field (M), with KO mice showing significantly less entries to the center zone $(\mathrm{N})$, showing a slight anxiety phenotype. $\mathrm{N}=16 \mathrm{WT}, 18 \mathrm{Gpc} 4 \mathrm{KO}$, statistics by 2-way ANOVA (M) or $T$-test $(\mathrm{N})$, bar graph mean \pm s.e.m., individual points represent mice. 

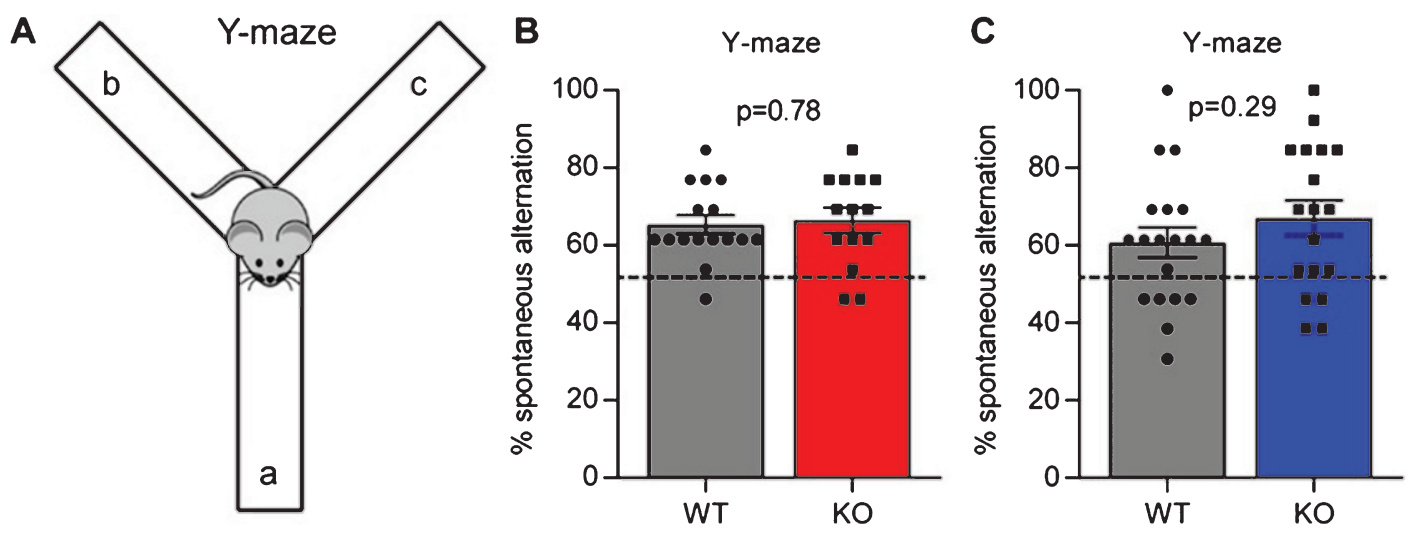

Fig. 3. Gpc4 KO mice show no deficits in working memory. A. Schematic of the Y-maze used to test spontaneous alternation and working memory. B. Gpc4 KO and WT P90 mice on a C57B16/J background perform better than chance in the Y-maze spontaneous alternation test, with no significant difference in performance between genotypes. N=16 WT, 14 Gpc4 KO. C. Gpc4 KO and WT P90 mice on an FVB background perform better than chance in the Y-maze spontaneous alternation test, with no significant difference in performance between genotypes. $\mathrm{N}=19 \mathrm{WT}, 18 \mathrm{Gpc} 4 \mathrm{KO}$ (FVB). Statistics by $T$-test, bar graph mean \pm s.e.m., individual points represent mice, dashed line represents chance (50\% spontaneous alternation).

(i.e. chance) suggests mice are deficient in working memory.

For mice on a C57B16/J background, there was no difference in the amount of spontaneous alternation between the WT and Gpc4 KO (\% spontaneous alternation: WT $65.4 \pm 2.4 \%$, KO $66.5 \pm 3.2 \% ; p=0.78$ by $T$-test; $\mathrm{N}=16 \mathrm{WT}, 14 \mathrm{KO}$; Fig. 3B). In addition, mice of both genotypes performed significantly better than chance in switching between the different arms of the maze ( $T$-test vs chance: WT $p<0.0001$; $\mathrm{KO} p<0.0001)$, demonstrating working memory is intact. For mice on an FVB background we detected no significant difference between genotypes in their performance in the Y-maze (\% spontaneous alternation: WT $60.7 \pm 3.9 \%$, KO $67.1 \pm 4.5 \%$; $p=0.29$ by $T$-test; N $=19$ WT, 18 KO; Fig. 3C), and both genotypes also performed significantly better than chance in switching between arms ( $T$-test vs chance: WT $p=0.009$; KO $p=0.0005)$. Therefore Gpc4 KO mice have intact working memory.

\section{Adult Gpc4 KO mice do not show anxiety-related behavior}

In the open field test there was no significant difference between each genotype in the time they spent in the center zone or the edge zone, although Gpc4 KO mice on an FVB background had significantly less entries to the center zone, suggesting no overt (or a subtle) anxiety phenotype. To explore this further we performed a light-dark test. A dark box was placed at one end of the open field arena, putting one third of the arena in darkness. The mouse was allowed to explore for 15 minutes and the time spent in the light chamber (low anxiety) compared to the dark chamber (higher anxiety) recorded (Fig. 4A). A WT mouse will typically spend more time in the dark chamber than the light chamber, and an increased time in the light would suggest decreased anxiety. Both the WT and Gpc4 KO mice on a C57B16/J background spent significantly more time in the dark chamber than in the light chamber, and no significant differences between genotypes were detected (WT: time light $286 \pm 26 \mathrm{sec}$, dark $610 \pm 26 \mathrm{sec} ; p<0.001 ; \mathrm{KO}$ : time light $314 \pm 21 \mathrm{sec}$, dark $582 \pm 22 \mathrm{sec} ; p<0.001$; statistics 2-way ANOVA; N = 15 WT, 13 Gpc4 KO; Fig. 4B). Further, when analyzing the number of times the mouse transitioned between the dark and the light zone, there was also no significant difference between genotypes (WT: $58 \pm 10$ entries; KO $42 \pm 7$ entries; $T$-test $p=0.21$; Fig. $4 C$ ). A similar result was obtained when testing mice on an FVB background for time in each zone (WT: time light $287 \pm 23 \mathrm{sec}$, dark $609 \pm 23 \mathrm{sec} ; p<0.001$; KO: time light $308 \pm 25 \mathrm{sec}$, dark $589 \pm 25 \mathrm{sec} ; p<0.001$; statistics 2-way ANOVA; N=19 WT, 18 Gpc4 KO; Fig. 4C) and transitions between zones (WT: $53 \pm 6$ entries; KO $53 \pm 5$ entries; $T$-test $p=0.98$; Fig. 4E). Thus, Gpc4 KO mice do not show signs of altered anxiety behavior in multiple tests.

\section{Adult Gpc4 KO mice show deficits in social novelty}

Given the synaptic deficits in Gpc4 KO mice, and the link to decreased levels of Gpc4 and ASD, 
A

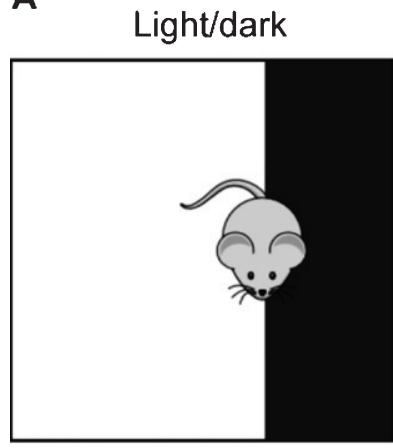

Light
B

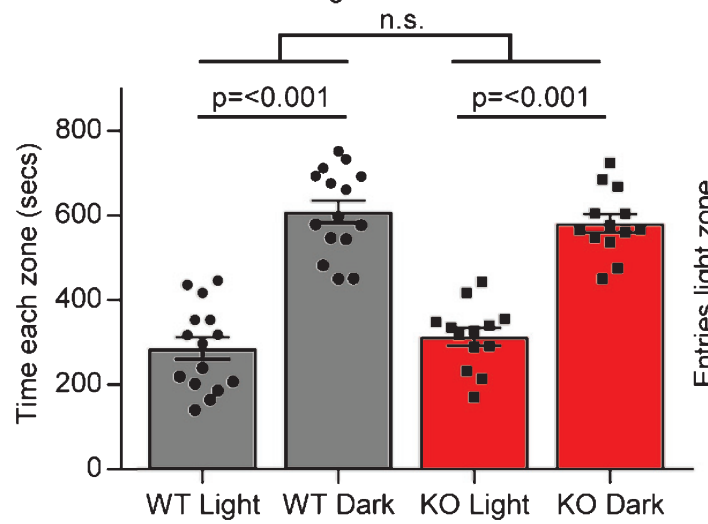

D

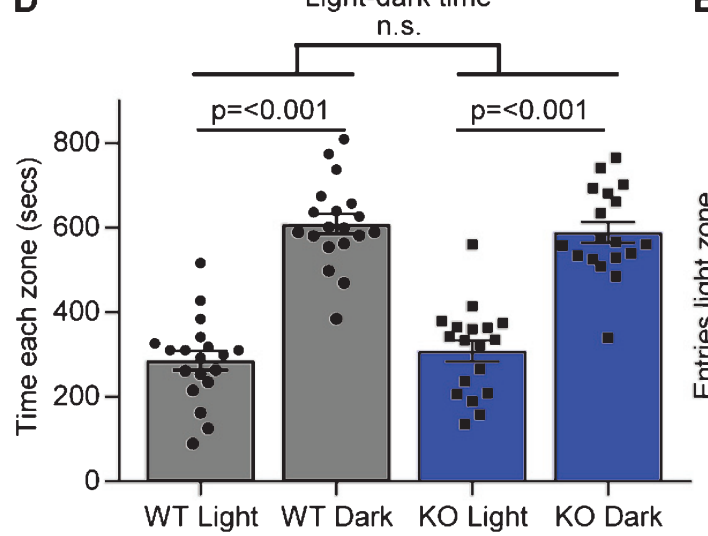

C

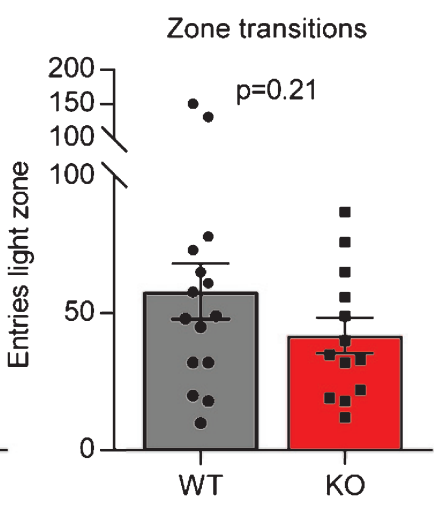

$\mathbf{E}$

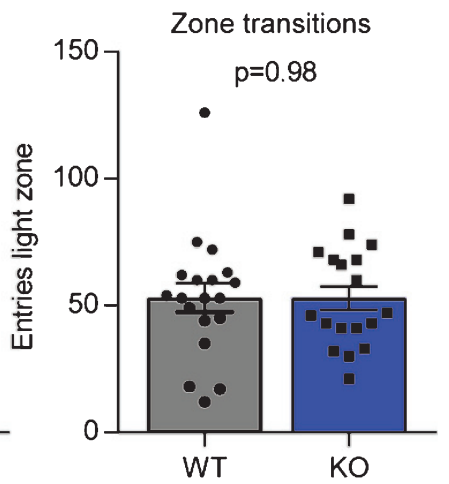

Fig. 4. Gpc4 KO mice show no anxiety in the light-dark test. A. Schematic of the light-dark chamber used to test anxiety. B-C. Gpc4 KO and WT P90 mice on a C57B16/J background are indistinguishable from each other in time spent in the light or dark chamber over a 15 minute period (B) and in transitions between the dark and the light zone (C). N=15 WT, 13 Gpc4 KO. D-E. Gpc4 KO and WT P90 mice on an FVB background are indistinguishable from each other in time spent in the light or dark chamber over a 15 minute period (D) and in transitions between the dark and the light zone (E). N=19 WT, 18 Gpc4 KO. Statistics by 2-way ANOVA (B, D) or T-test (C, E), bar graph mean \pm s.e.m., individual points represent mice.

we asked if Gpc4 KO mice showed any deficits in social behaviors that are characteristically altered in mice that have mutations linked to ASD [4, 19]. We assessed this using a 3 chamber social interaction test, where in the first phase the mouse chooses between a chamber containing an unknown stimulus mouse and an empty chamber (social interest) (Fig. 5A), and in the second phase the mouse chooses between a chamber containing the original stimulus mouse and a novel stimulus mouse (social novelty) (Fig. 5D). As mice are social animals, it is expected that a WT mouse will spend more time investigating the stimulus mouse than the empty chamber in the first phase, and more time investigating the novel mouse than the original stimulus mouse in the second phase. For both tests the total time spent in the chamber, as well as the time spent interacting with the mouse/object are recorded over the 10 minute test period.
In the social interest phase, for mice on a C57B16/J background, the WT mice spent significantly more time in the chamber containing the stimulus mouse than the empty chamber, whereas the Gpc4 KO mice did not spend significantly more time in one chamber than the other (WT: time empty chamber $203 \pm 17 \mathrm{sec}$, stimulus mouse $273 \pm 13 \mathrm{sec}$; $p=0.02$; KO: time empty chamber $220 \pm 22 \mathrm{sec}$, stimulus mouse $264 \pm 25 \mathrm{sec} ; p=0.13$; statistics 2way ANOVA; N=13 WT, 13 Gpc4 KO; Fig. 5B). When analyzing time in contact with the stimulus mouse or the empty chamber, both the WT and Gpc4 KO spent more time in contact with the stimulus mouse chamber than the empty chamber (WT: contact empty chamber $79 \pm 10 \mathrm{sec}$, stimulus mouse $117 \pm 11 \mathrm{sec} ; p=0.06$; KO: contact empty chamber $83 \pm 14 \mathrm{sec}$, stimulus mouse $125 \pm 18 \mathrm{sec}$; $p=0.04$; Fig. $5 \mathrm{C}$ ), overall suggesting a subtle social 
A

A Social interaction

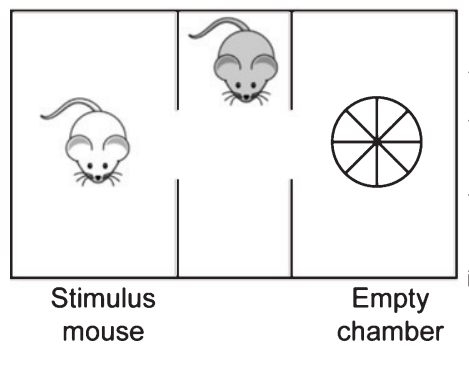

D

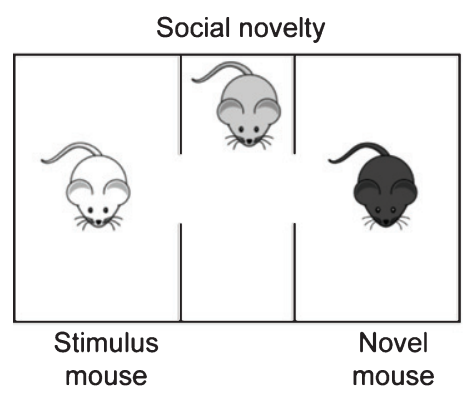

G Social Interest, Zone Time
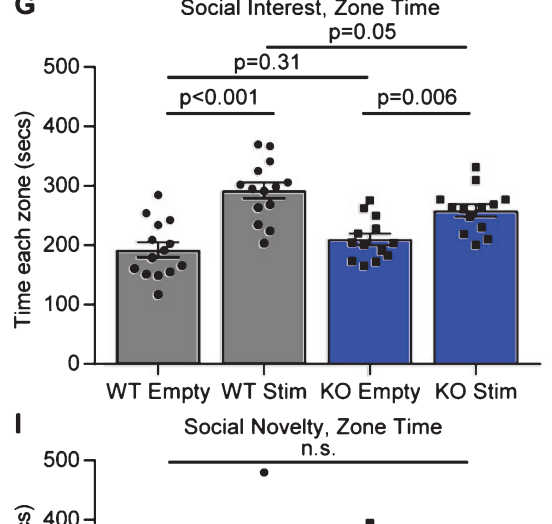

B Social Interest, Zone Time

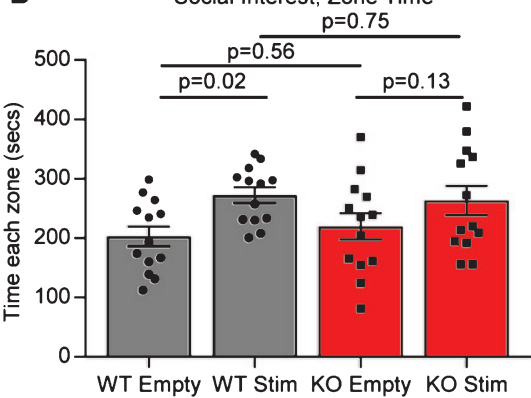

E
C Social Interest, Contact Time

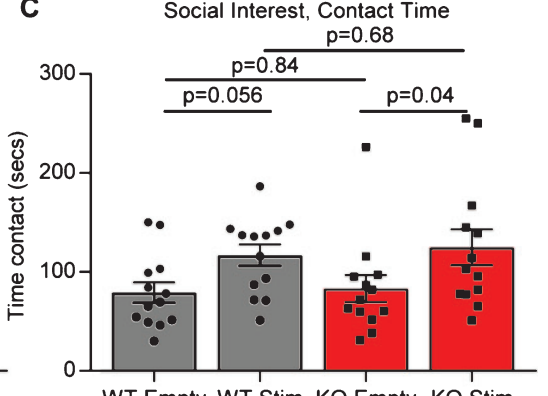

F Social Novelty, Contact Time

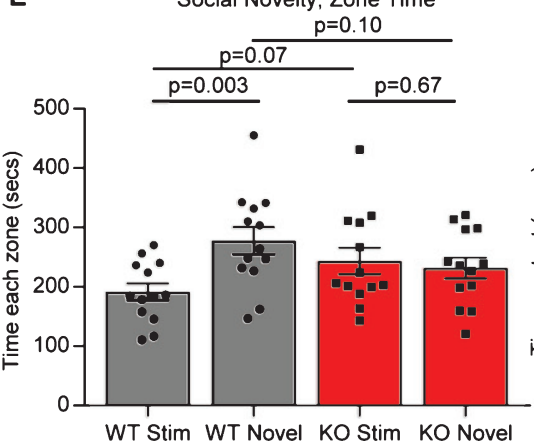

WT Stim WT Novel KO Stim KO Novel

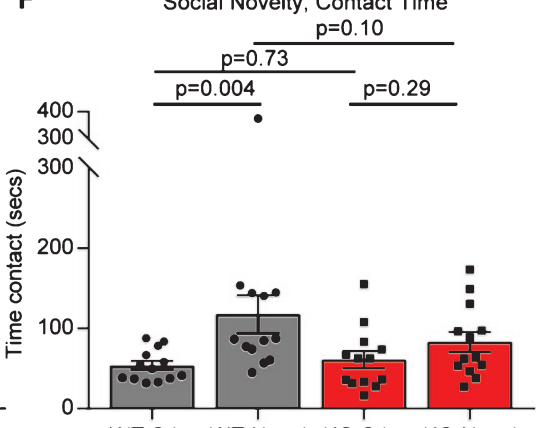

H Social Interest, Contact Time

WT Stim WT Novel KO Stim KO Novel
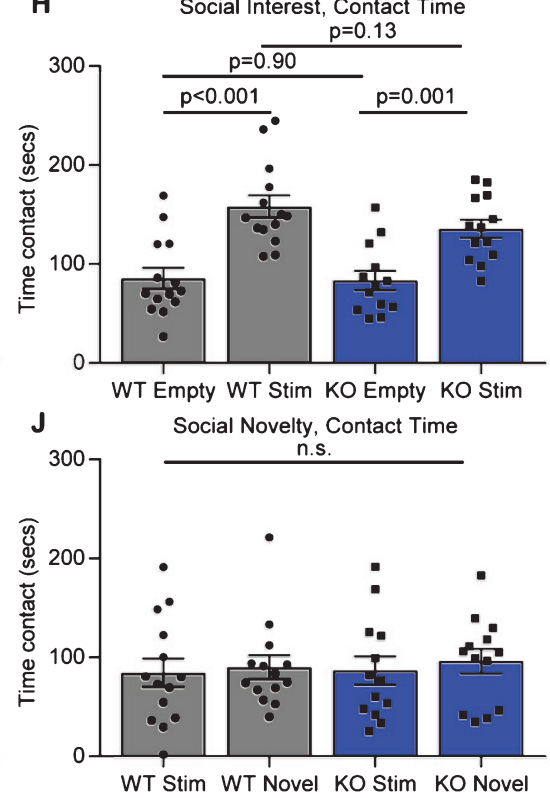

Fig. 5. Gpc4 KO mice have social interaction deficits. A. Schematic of the 3-chamber social-interaction apparatus. B-C. C57B16/J P90 Gpc4 KO mice do not show preference for a stimulus mouse over an object over a 10 minute period, whereas WT mice do, for time in the chamber (B) but not time in contact (C). D. Schematic of the 3-chamber social-novelty apparatus. E-F. C57B16/J P90 Gpc4 KO mice do not show preference for a novel mouse over the familiar stimulus mouse over a 10 minute period whereas WT mice do, both for time in the chamber (E) and time in contact (F). N = $13 \mathrm{WT}, 13 \mathrm{Gpc} 4 \mathrm{KO}$, statistics by 2-way ANOVA, bar graph mean \pm s.e.m., individual points represent mice. G-H. FVB P90 Gpc4 KO and WT mice both show preference for a stimulus mouse over an object over a 10 minute period, both for time in the chamber (G) and time in contact (H). I-J. FVB P90 Gpc4 KO and WT mice do not show preference for a novel mouse over the familiar stimulus mouse over a 10 minute period, both for time in the chamber (I) and time in contact (J). N=14 WT, $13 \mathrm{Gpc} 4 \mathrm{KO}$, statistics by 2-way ANOVA, bar graph mean \pm s.e.m., individual points represent mice. 
interest deficit in Gpc4 KO mice. In the social novelty phase, the WT mice performed as expected and spent significantly more time in the chamber containing the novel mouse than the original stimulus mouse, whereas the Gpc4 KO mice showed no preference for either mouse (WT: time stimulus mouse $192 \pm 14 \mathrm{sec}$, novel mouse $278 \pm 23 \mathrm{sec} ; p=0.003$; KO: time stimulus mouse $244 \pm 22 \mathrm{sec}$, novel mouse $232 \pm 18 \mathrm{sec} ; p=0.67 ;$ Fig. 5E). Analyzing the time spent in contact with either mouse revealed the same result, demonstrating a social novelty deficit in Gpc4 KO mice (WT: contact stimulus mouse $54 \pm 6 \mathrm{sec}$, novel mouse $118 \pm 24 \mathrm{sec} ; p=0.004 ; \mathrm{KO}$ : contact stimulus mouse $61 \pm 11 \mathrm{sec}$, novel mouse $83 \pm 12$ sec; $p=0.29$; Fig. 5F).

For mice on an FVB background, both WT and Gpc4 KO mice displayed a significant preference for the chamber containing the stimulus mouse over the empty chamber in the social interest test, although the differential was smaller in the Gpc4 KO (WT: time empty chamber $193 \pm 13 \mathrm{sec}$, stimulus mouse $292 \pm 13 \mathrm{sec} ; p<0.001$; KO: time empty chamber $210 \pm 10 \mathrm{sec}$, stimulus mouse $258 \pm 10 \mathrm{sec}$; $p=0.006$; statistics 2-way ANOVA; $\mathrm{N}=14 \mathrm{WT}, 13$ Gpc4 KO; Fig. 5G). Both genotypes also spent significantly more time in contact with the stimulus mouse than the empty chamber (WT: contact empty chamber $86 \pm 11 \mathrm{sec}$, stimulus mouse $158 \pm 11 \mathrm{sec} ; p<0.001$; KO: contact empty chamber $84 \pm 10 \mathrm{sec}$, stimulus mouse $136 \pm 10 \mathrm{sec} ; p=0.001$; Fig. $5 \mathrm{H}$ ). In the social novelty test, no significant differences were detected by 2-way ANOVA between the WT and KO, or within each condition for time in the vicinity of or in contact with the novel and stimulus mouse (WT: time stimulus mouse $210 \pm 21 \mathrm{sec}$, novel mouse $256 \pm 22 \mathrm{sec}$; KO: time stimulus mouse $220 \pm 22 \mathrm{sec}$, novel mouse $235 \pm 19$ sec; Fig. 5I) and (WT: contact stimulus mouse $84 \pm 14 \mathrm{sec}$, novel mouse $90 \pm 12 \mathrm{sec}$; KO: contact stimulus mouse $87 \pm 14 \mathrm{sec}$, novel mouse $96 \pm 12 \mathrm{sec}$; Fig. 5J). Thus, the strongest deficit is in social novelty for Gpc4 KO mice on a C57B16/J background, a common finding in other mice with mutations linked to ASD [25].

\section{DISCUSSION}

We set out to investigate if Gpc4 KO mice display alterations in behavior, due to the important role of Gpc4 in regulating synaptic development and GluA1 AMPARs, and the link between decreased Gpc4 levels and ASD. We found at juvenile ages (P14) Gpc4 $\mathrm{KO}$ mice are hyperactive, and at adult ages $\mathrm{Gpc} 4 \mathrm{KO}$ mice show social novelty deficits characteristic of ASD. We did not detect any other significant differences in adult Gpc4 KO mice in a broad neurological screen, in working memory performance in the Ymaze, or in anxiety, showing a specificity of effect on social behavior.

Beyond behavioral alterations, we also determined that Gpc4 KO mice are lighter than WT counterparts at 3 months of age, significantly so on an FVB background. Gpc 4 has been identified as a circulating adipokine whose levels positively correlate with body mass index in humans, and can regulate adipose distribution and insulin signaling [26, 27]. Therefore the decreased bodyweight in Gpc4 KO mice may be due to less adipose deposition.

Gpc4 regulates synaptic levels of GluA1, and many of the behaviors we chose to analyze have been shown to be altered in GluA1 KO mice. For example, GluA1 KO mice show novelty-induced hyperactivity and social interaction deficits, effects we detected in juvenile (hyperactivity) and adult (social interaction deficit) Gpc4 KO mice [28, 29]. The Gpc4 KO juvenile hyperactivity was corrected by $\mathrm{P} 21$, and it is unclear if this is due to a decrease in anxiety with age, or if the hyperactivity at P14 is due to the novel environment (the P21 mice were the same mice that had been exposed to the environment at P14). The juvenile hyperactivity (P14) coincides with the time we have detected a deficit in synaptic transmission in the hippocampus of Gpc4 KO mice, where CA1 neuron mEPSCs are decreased in amplitude and synapses contain less GluA1 AMPARs [4]. We have further identified a decrease in GluA1 at synapses in the visual system at P6, suggesting a general deficit in synaptic development throughout the brain in the absence of Gpc4 [13]. In future it will be important to determine which neurons and synapses are responsible for inducing juvenile hyperactivity in the absence of Gpc4.

GluA1 KO mice show deficits in spontaneous alternation in the Y-maze [30], while spatial learning is intact shown by normal performance in the Morris water maze [31]. We therefore hypothesized that Gpc4 KO mice may show deficits in working memory assayed in the Y-maze, due to decreased levels of synaptic GluA1 in the Gpc4 KO. We detected no difference in performance, however, between the genotypes at 3 months of age, with both WT and Gpc4 KO mice performing above chance and displaying intact working memory. It may be that at younger ages (P14-P28), when we detected a significant decrease in synaptic GluA1 in Gpc4 KO compared to WT, that 
the KO would be impaired in this task, which will be important to determine in the future.

In adult mice the major deficit in the Gpc4 KO was in behaviors linked to sociability: social interaction and social novelty, a phenotype also observed in GluA1 KO mice [29]. These are phenotypes typically seen in mice with mutations linked to ASD [25, 32, 33]. On a C57B16/J background there was a subtle social interaction deficit in Gpc4 KO mice. Gpc4 KO did not show a significant preference for spending time in the chamber with the novel mouse compared to the chamber with the novel object, whereas WT mice showed the expected social behavior and preferred the novel mouse to the object. This difference between genotypes was absent when analyzing time spent in contact with the mouse or the object. For the social novelty phase, for both time in the chamber and time in contact, Gpc4 KO mice failed to show a preference for the novel mouse over the familiar stimulus mouse, whereas WT littermates showed a strong preference for the novel mouse as expected. This effect is unlikely to be due to an olfactory deficit, as in neurological screening the Gpc4 KO and WT were indistinguishable in their response to an olfactory cue. Interestingly, when analyzing these same behaviors on an FVB background, Gpc4 KO mice performed at a similar level to WT in both the social interest and social novelty tasks (although the time the Gpc4 KO spent in the chamber with the stimulus mouse was significantly less than WT in the social interest task). Both WT and Gpc4 KO mice on an FVB background failed to show the expected preference for the novel mouse in the social novelty task. This was unexpected, as even though genetic background can influence the ability of mice to perform this task, it has previously been shown that WT FVB mice are able to perform it [20]. Further strain specific effects were seen in performance in the open field, where Gpc4 KO mice on a C57B16/J background were indistinguishable from WT, whereas Gpc4 KO mice on an FVB background showed a decrease in rearing and less entries to the center of the arena. However, the FVB Gpc4 KO mice performed the same as WT in the light:dark test, suggesting no overt anxiety phenotype is present. Nevertheless, on a C57B16/J background, Gpc4 KO mice show an inability to distinguish between a novel and a familiar mouse, thus revealing a deficit in social novelty that is a characteristic feature of mice with mutations linked to ASD.

Overall we demonstrate that Gpc4 KO mice show behavioral alterations that change with developmental stage, and that the phenotypes detected are consistent with those in mice with decreased levels of synaptic GluA1 or mutations linked to ASD. We analyzed only male mice, as Gpc4 is on the $\mathrm{X}$ chromosome, and in future it will be interesting to determine if female mice lacking Gpc4 show the same behavioral alterations, and if female mice heterozygous for Gpc4 (where expression of Gpc4 will be mosaic due to random inactivation of the $\mathrm{X}$ chromosome) show any behavioral abnormalities. These experiments were performed in mice globally lacking Gpc4. In future it will be important to repeat these experiments in mice with cell-specific removal of Gpc4 (e.g. astrocyte or principal neuron), to determine in which cell type loss of $\mathrm{Gpc} 4$ is contributing to each phenotype, and if this varies with developmental stage, to give further insight into the role of $\mathrm{Gpc} 4$ in synaptic development, plasticity and behavior.

\section{ACKNOWLEDGMENTS}

We thank C. Farrokhi in the Salk Institute Behavioral Testing core for assistance with experimental design and training in relevant behavioral tests, and C. Heller for assistance in training. This work was supported by NIH NINDS R01 NS089791 to NJA, and by NINDS Neuroscience Core Grant P30 NS072031 to the Behavioral Testing core.

\section{CONFLICT OF INTEREST}

The authors have no conflict of interest to report.

\section{REFERENCES}

[1] Allen NJ. Astrocyte regulation of synaptic behavior. Annu Rev Cell Dev Biol. 2014;30:439-63.

[2] Farhy-Tselnicker I, Allen NJ. Astrocytes, neurons, synapses: A tripartite view on cortical circuit development. Neural Development. 2018;13(7):1-12.

[3] Ullian EM, Sapperstein SK, Christopherson KS, Barres BA. Control of synapse number by glia. Science. 2001;291(5504):657-61.

[4] Allen NJ, Bennett ML, Foo LC, Wang GX, Chakraborty C, Smith SJ, Barres BA. Astrocyte glypicans 4 and 6 promote formation of excitatory synapses via GluA1 AMPA receptors. Nature. 2012;486(7403):410-4.

[5] Filmus J, Capurro M, Rast J. Glypicans. Genome Biology. 2008;9(5):224.

[6] Farhy-Tselnicker I, Boisvert MM, Allen NJ. The role of neuronal versus astrocyte-derived heparan sulfate proteoglycans in brain development and injury. Biochemical Society Transactions. 2014;42(5):1263-9.

[7] Luxardi G, Galli A, Forlani S, Lawson K, Maina F, Dono R. Glypicans are differentially expressed during patterning and neurogenesis of early mouse brain. Biochem Biophys Res Commun. 2007;352(1):55-60. 
[8] Watanabe K, Yamada H, Yamaguchi Y. K-glypican: A novel GPI-anchored heparan sulfate proteoglycan that is highly expressed in developing brain and kidney. J Cell Biol. 1995;130(5):1207-18.

[9] de Wit J, O'Sullivan ML, Savas JN, Condomitti G, Caccese MC, Vennekens KM, Yates JR 3rd, Ghosh A. Unbiased discovery of glypican as a receptor for LRRTM4 in regulating excitatory synapse development. Neuron. 2013;79(4):696711.

[10] Siddiqui TJ, Tari PK, Connor SA, Zhang P, Dobie FA, She K, Kawabe H, Wang YT, Brose N, Craig AM. An LRRTM4HSPG complex mediates excitatory synapse development on dentate gyrus granule cells. Neuron. 2013;79(4):680-95.

[11] Condomitti G, Wierda KD, Schroeder A, Rubio SE, Vennekens KM, Orlandi C, Martemyanov KA, Gounko NV, Savas JN, de Wit J. An Input-Specific Orphan Receptor GPR158-HSPG Interaction Organizes Hippocampal Mossy Fiber-CA3 Synapses. Neuron. 2018;100(1):201-15.e9.

[12] Cahoy JD, Emery B, Kaushal A, Foo LC, Zamanian JL, Christopherson KS, Xing Y, Lubischer JL, Krieg PA, Krupenko SA, Thompson WJ, Barres BA. A transcriptome database for astrocytes, neurons, and oligodendrocytes: A new resource for understanding brain development and function. J Neurosci. 2008;28(1):264-78.

[13] Farhy-Tselnicker I, van Casteren ACM, Lee A, Chang VT, Aricescu AR, Allen NJ. Astrocyte-Secreted Glypican 4 Regulates Release of Neuronal Pentraxin 1 from Axons to Induce Functional Synapse Formation. Neuron. 2017;96(2):428-45.

[14] Ko JS, Pramanik G, Um JW, Shim JS, Lee D, Kim KH, Chung G-Y, Condomitti G, Kim HM, Kim H, de Wit J, Park K-S, Tabuchi K, Ko J. PTP $\sigma$ functions as a presynaptic receptor for the glypican-4/LRRTM4 complex and is essential for excitatory synaptic transmission. Proceedings of the National Academy of Sciences. 2015;112(6):1874-9.

[15] Lesch KP, Timmesfeld N, Renner TJ, Halperin R, Roser C, Nguyen TT, Craig DW, Romanos J, Heine M, Meyer J, Freitag C, Warnke A, Romanos M, Schafer H, Walitza S, Reif A, Stephan DA, Jacob C. Molecular genetics of adult ADHD: Converging evidence from genome-wide association and extended pedigree linkage studies. J Neural Transm. 2008;115(11):1573-85.

[16] Calboli FC, Tozzi F, Galwey NW, Antoniades A, Mooser V, Preisig M, Vollenweider P, Waterworth D, Waeber G, Johnson MR, Muglia P, Balding DJ. A genome-wide association study of neuroticism in a population-based sample. PLoS One. 2010;5(7):e11504.

[17] Gandal MJ, Haney JR, Parikshak NN, Leppa V, Ramaswami G, Hartl C, Schork AJ, Appadurai V, Buil A, Werge TM, Liu C, White KP, Horvath S, Geschwind DH. Shared molecular neuropathology across major psychiatric disorders parallels polygenic overlap. Science. 2018;359(6376):693-7.

[18] Potkin SG, Macciardi F, Guffanti G, Fallon JH, Wang Q, Turner JA, Lakatos A, Miles MF, Lander A, Vawter MP, Xie $\mathrm{X}$. Identifying gene regulatory networks in schizophrenia. Neuroimage. 2010;53(3):839-47.

[19] Doan RN, B.-I. Bae, Cubelos B, Chang C, Hossain AA, S. Al-Saad, Mukaddes NM, Oner O, M. Al-Saffar, Balkhy S, Gascon GG, Nieto M, Walsh CA. Mutations in Human Accelerated Regions Disrupt Cognition and Social Behavior. Cell. 2016;167(2):341-54.e12.

[20] Moy SS, Nadler JJ, Perez A, Barbaro RP, Johns JM, Magnuson TR, Piven J, Crawley JN. Sociability and preference for social novelty in five inbred strains: An approach to assess autistic-like behavior in mice. Genes, Brain and Behavior. 2004;3(5):287-302.

[21] Lalonde R, Marchetti N, Strazielle C. Primary neurologic screening and motor coordination of Dstdt-J mutant mice (dystonia musculorum) with spinocerebellar atrophy. Physiology \& Behavior. 2005;86(1):46-51.

[22] Miedel CJ, Patton JM, Miedel AN, Miedel ES, Levenson JM. Assessment of Spontaneous Alternation, Novel Object Recognition and Limb Clasping in Transgenic Mouse Models of Amyloid and Tau Neuropathology. JoVE. 2017;(123):e55523.

[23] Takao K, Miyakawa T. Light/dark Transition Test for Mice. JoVE. 2006;(1):e104.

[24] Yang M, Silverman JL, Crawley JN. Automated ThreeChambered Social Approach Task for Mice. Current Protocols in Neuroscience. 2011;56(1):8.26.1-8.26.16.

[25] Silverman JL, Yang M, Lord C, Crawley JN. Behavioural phenotyping assays for mouse models of autism. Nature Reviews Neuroscience. 2010;11:490.

[26] Yoo HJ, Hwang SY, Cho GJ, Hong HC, Choi HY, Hwang TG, Kim SM, Bluher M, Youn BS, Baik SH, Choi KM. Association of glypican- 4 with body fat distribution, insulin resistance, and nonalcoholic fatty liver disease. J Clin Endocrinol Metab. 2013;98(7):2897-901.

[27] Ussar S, Bezy O, Blüher M, Kahn CR. Glypican-4 enhances insulin signaling via interaction with the insulin receptor and serves as a novel adipokine. Diabetes. 2012;61(9):2289-98.

[28] Maksimovic M, Vekovischeva OY, Aitta-aho T, Korpi ER. Chronic Treatment with Mood-Stabilizers Attenuates Abnormal Hyperlocomotion of GluA1-Subunit Deficient Mice. PLOS ONE. 2014;9(6):e100188.

[29] Barkus C, Feyder M, Graybeal C, Wright T, Wiedholz L, Izquierdo A, Kiselycznyk C, Schmitt W, Sanderson DJ, Rawlins JNP, Saksida LM, Bussey TJ, Sprengel R, Bannerman D, Holmes A. Do GluA1 knockout mice exhibit behavioral abnormalities relevant to the negative or cognitive symptoms of schizophrenia and schizoaffective disorder? Neuropharmacology. 2012;62(3):1263-72.

[30] Bannerman D, Deacon R, Brady S, Bruce A, Sprengel R, Seeburg P, Rawlins J. A comparison of GluR-A-deficient and wild-type mice on a test battery assessing sensorimotor, affective, and cognitive behaviors. Behavioral Neuroscience. 2004;118(3):643-47.

[31] Zamanillo D, Sprengel R, Hvalby O, Jensen V, Burnashev N, Rozov A, Kaiser KM, Koster HJ, Borchardt T, Worley P, Lubke J, Frotscher M, Kelly PH, Sommer B, Andersen P, Seeburg PH, Sakmann B. Importance of AMPA receptors for hippocampal synaptic plasticity but not for spatial learning. Science. 1999;284(5421):1805-11.

[32] Jamain S, Radyushkin K, Hammerschmidt K, Granon S, Boretius S, Varoqueaux F, Ramanantsoa N, Gallego J, Ronnenberg A, Winter D, Frahm J, Fischer J, Bourgeron T, Ehrenreich H, Brose N, Reduced social interaction and ultrasonic communication in a mouse model of monogenic heritable autism. Proceedings of the National Academy of Sciences. 2008;105(5):1710-5.

[33] Scearce-Levie K, Roberson ED, Gerstein H, Cholfin JA, Mandiyan VS, Shah NM, Rubenstein JLR, Mucke L. Abnormal social behaviors in mice lacking Fgf17. Genes, Brain and Behavior. 2008;7(3):344-54. 